\title{
Isolation of a gastric campylobacter-like organism from the stomach of four Rhesus monkeys, and identification as Campylobacter pylori
}

\author{
D. G. NEWELL, M. J. HUDSON* and A. BASKERVILLE
}

\section{Experimental Pathology Laboratory and "Bacterial Metabolism Research Laboratory, PHLS Centre for Applied Microbiology and Research, Porton Down, Salisbury SP4 QJG}

\begin{abstract}
Summary. Campylobacter-like organisms, isolated from the gastric antrum of Rhesus monkeys, were compared with Campylobacter jejuni and $C$. pylori. They were similar to $C$. pylori by light microscopy, in ultrastructural morphology, in enzymic, fatty-acidmethyl-ester, and protein-profile analysis, and in antigenic reactivity with rabbit antisera to $C$. jejuni and $C$. pylori and with $C$. pylori-specific monoclonal antibody. Because this natural infection of the Rhesus monkey is associated with chronic gastritis, resembling the disease in humans colonised with $C$. pylori, we recommend the animal as a model for the investigation of human gastritis.
\end{abstract}

\section{Introduction}

It is widely recognised that histologically diagnosed chronic gastritis in man is frequently accompanied by colonisation of the antral mucosa with Campylobacter pylori (Blaser, 1987). Although limited human volunteer studies (Marshall et al., 1985; Morris and Nicholson, 1987) support a pathogenic role for this organism in chronic gastritis, such uncontrolled studies are subject to criticism. The role of $C$. pylori in gastritis needs, therefore, to be investigated with suitable animal models, which may be useful also in establishing effective antimicrobial therapy. In the International Workshop on C. pylori Infections, at Keystone in 1987, the development of a good animal model of such gastritis was considered by the participants as the primary research priority (A. Lee, personal communication).

We have recently studied several primate species for susceptibility to gastritis (Baskerville and Newell, 1987), and have now isolated a gastric campylobacter-like organism (GCLO) from the chronically inflamed gastric mucosa of several Rhesus monkeys. To classify these isolates we have compared their morphological, structural, biochemical and antigenic properties with those of $C$. jejuni and C. pylori.

\section{Materials and methods}

\section{Animals}

Seven Rhesus monkeys (Macaca mulatta) aged 2-8

Received 1 Dec. 1987; accepted 9 Feb. 1988. years, which came to autopsy for unrelated reasons, were examined microbiologically. The histopathological findings in the gastric mucosa of these animals have been described by Baskerville and Newell (1987).

\section{Bacterial strains}

C. jejuni strain 81116 , isolated from human faeces, was kindly supplied by the Public Health Laboratory, Southampton. C. pylori strain NCTC 11638 was isolated from human gastric mucosa by Dr B. Marshall (Perth, Western Australia) and kindly supplied by Dr M. Skirrow (Royal Infirmary, Worcester). These isolates possessed the biochemical and antigenic properties characteristic of their respective species (Newell et al., 1984; Newell, 1987).

GCLO strains 87008,87010 and 87012 were isolated from the gastric mucosa of Rhesus monkeys (see below).

\section{Culture and storage of campylobacter-like organisms}

Tissue samples from the gastric antrum, fundus, pylorus and duodenum were processed within $1 \mathrm{~h}$ of death. Pieces of biopsy material c. $5 \mathrm{~mm}^{2}$ were smeared directly on to agar plates containing defibrinated horse blood $5 \%$ and selective antibiotics (Skirrow, 1977). In some cases tissue was snap frozen and stored in liquid nitrogen before culture. Plates were cultured for up to 5 days at $37^{\circ} \mathrm{C}$ in micro-aerophilic conditions (micro-aerophilic gas generating kit, Oxoid). GCLOs, recognised by colonial morphology, were sub-cultured on blood agar alone, for purity, and identified by light microscopy with phase contrast and Gram's staining, by the catalase and oxidase reactions, and by the rapid hydrolysis of urea (Owen et $a l ., 1985)$. Isolates were suspended in proteose peptone $1 \%$ (Oxoid) with glycerol $10 \%$, and were snap frozen and stored in liquid nitrogen. 


\section{$S D S-P A G E$}

The total protein profile of $C$. jejuni strain 81116, $C$. pylori NCTC 11638 and the monkey isolates was examined on a $10-25 \%$ gradient SDS-polyacrylamide gel as described by Newell (1987).

\section{Western blotting}

SDS-PAGE gels of total protein profiles were electroblotted on to nitrocellulose paper with a semi-dry blotter (Dako Ltd)-see Kyhse-Andersen (1984). The blots were incubated with rabbit antisera to $C$. jejuni (Newell et al., 1984) and C. pylori (Newell, 1987) and a mouse monoclonal antibody (CP1) specific for C. pylori (Newell, 1988). Bound antibodies were detected with goat antirabbit or goat anti-mouse IgG coupled to peroxidase (Bio-Rad Ltd) as described by Newell (1987).

\section{Cell fatty acid $(F A)$ analysis}

Cell FAs were analysed by capillary gas-liquid chromatography (GLC) and GLC mass-spectrometry of their FA methyl esters (FAME) as described by Wait and Hudson (1985).

\section{Results}

GCLOs were isolated from four of the seven Rhesus monkeys examined, and could be cultured from snap-frozen as well as from fresh biopsy material. Morphologically, these organisms were motile Gram-negative rods, S-shaped or spiral, and frequently with characteristic ox-bow forms. By transmission electronmicroscopy the bacteria had the morphological features of $C$. pylori (fig. 1) including unipolar multiple sheathed flagella with

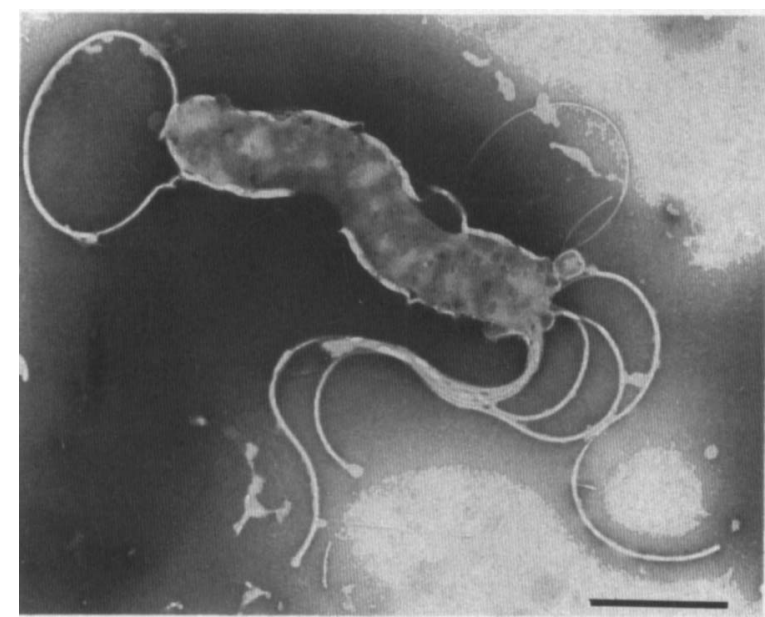

Fig. 1. Transmission electronmicrograph (with negative straining) of a gastric campylobacter-like organism from monkey stomach. Note the multiple unipolar sheathed flagella with terminal paddles. Bar $=1.0 \mu \mathrm{m}$. terminal paddles. Conversely $C$. jejuni had single bipolar unsheathed flagella.

All the isolates grew micro-aerophilically only, gave positive results in tests for oxidase and catalase, and produced large quantities of urease, similar to the $C$.pylori strain but unlike the $C$. jejuni strain which did not produce urease.

The FAME and lipid profiles of the monkey strains possessed major 14.0 and cyclopropane 19.0 acids, together with $18 \cdot 0$, 3-hydroxy 16.0 and 3 hydroxy 18.0 acids, characteristic of the Campylobacter genus. They lacked $16 \cdot 1$ acid; and the ratio of 18.0 to 16.0 acids was $>1$. This cell fatty acid profile was indistinguishable from that of $C$. pylori, but differed markedly from that of $C$. jejuni which possessed 16.1 acid and had an 18.0 to 16.0 ratio of $<0 \cdot 1$.

The SDS-PAGE total protein profile (fig. 2) showed no obvious major outer membrane proteins, such as that of $C$. jejuni $\left(43 \times 10^{3} \mathrm{~mol}\right.$. wt $)$, but had three notable proteins with mol. wt $\left(10^{3}\right) 62,56$ and 54 , similar to the $C$. pylori strain.

Western blots of the total protein profiles of $C$. jejuni, $C$. pylori and a monkey GCLO, incubated with rabbit antisera to $C$. jejuni and $C$. pylori, are shown in fig. 3. Multiple prominent protein antigens were detected in the monkey GCLO with both antisera. None of these antigens corresponded with $C$. jejuni antigens, although rabbit antiserum to $C$. jejuni did cross-react with several antigens of the monkey strain. The antigenic profiles of $C$. pylori and the monkey GCLO were identical, with rabbit antiserum to $C$. pylori; and they were very similar

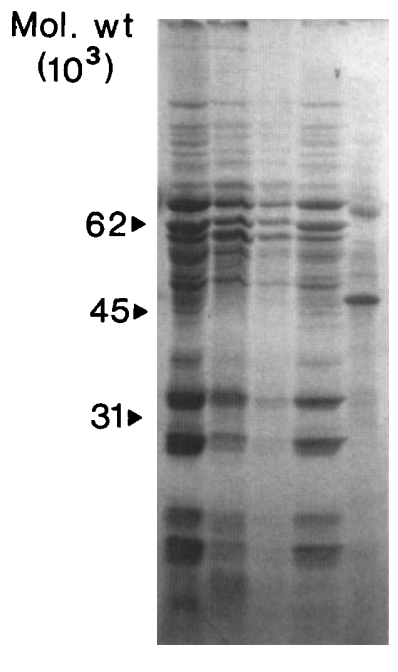

12345

Fig. 2. SDS-PAGE of the total protein profile of $C$. pylori 11638 (track 1), Rhesus monkey GCLO strains 87008 (track 2), 87010 (track 3) and 87012 (track 4), and C. jejuni 81116 (track 5). 


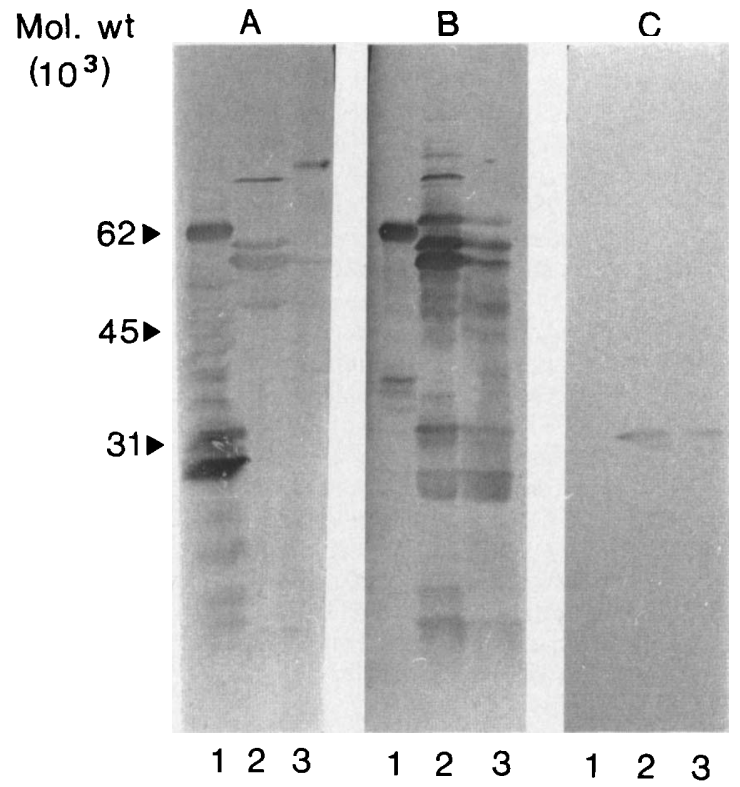

Fig. 3. Western blots of total protein profiles of $C$. jejuni 81116 (track 1), Rhesus monkey GCLO strain 87008 (track 2) and $C$. pylori NCTC 11638 (track 3), incubated with (A) rabbit antiserum to $C$. jejuni, (B) rabbit antiserum to $C$. pylori, (C) mouse monoclonal antibody to C. pylori.

with rabbit antiserum to $C$. jejuni. The $C$. pylorispecific monoclonal antibody reacted with a single protein $\left(31 \times 10^{3} \mathrm{~mol} . \mathrm{wt}\right)$ in the total protein profiles of both C. pylori and the monkey strain.

\section{Discussion}

The morphological, biochemical and antigenic properties of GCLOs isolated from the gastric antrum of Rhesus monkeys have been investigated. By Gram's stain and enzymic criteria, especially the rapid production of urease, these organisms were similar to C. pylori. This similarity was further supported by ultrastructural characteristics, in particular the possession of multiple unipolar sheathed flagella which distinguish C. pylori from other Campylobacter species (Jones et al., 1985). The total protein profiles of the monkey strains were unlike that of $C$. jejuni, with its characteristic single major outer membrane protein of (43-47) $\times$ $10^{3}$ mol. wt (Newell et al., 1984), but consistent with that of C. pylori (Megraud et al., 1985; Newell, 1987). Total protein antigenic profiles obtained by immunolabelling with rabbit antisera to $C$. jejuni

\section{REFERENCES}

Baskerville A, Newell D G 1987 Naturally occurring chronic gastritis and Campylobacter pylori infection in the rhesus and $C$. pylori demonstrated that a very close antigenic relationship existed with $C$. pylori but not with $C$. jejuni. However, some antigenic crossreactivity was seen with anti- $C$. jejuni serum. This was consistent with the degree of inter-species cross-reactivity previously ascribed to campylobacter flagellins (Newell, 1986, 1987). Moreover, a monoclonal antibody, CP1, which is directed against a protein $\left(31 \times 10^{3} \mathrm{~mol}\right.$. wt $)$ of all $C$. pylori strains but does not cross-react with $C$. jejuni (Newell, 1988), was found to react in Western blots with a protein of the same mol. wt in the monkey strains.

The value of fatty-acid analysis in the chemotaxonomy of Campylobacter species has been demonstrated by Wait and Hudson (1985); and C. pylori was shown to have a unique profile within the genus Campylobacter, unlike that of other genera examined (Hudson et al., 1988). The fatty-acid profiles of our monkey GCLOs were entirely consistent with those of the C.pylori strains previously studied.

All these investigations indicate that the monkey GCLO is indistinguishable from $C$. pylori by the techniques used.

Recently, campylobacter-like organisms associated with the gastric mucosa of several animals other than man have been reported. The GCLO isolated from the ferret was both morphologically (Fox et al., 1986) and by fatty-acid profile (Hudson et al., 1988) unlike $C$. pylori. Nevertheless, GCLOs apparently similar to $C$. pylori have been isolated from the monkey Macaca nemestrina (Bronston and Schoenknecht, 1988), a pig and a baboon (Jones and Eldridge, 1988). However, the relationship of the bacterial colonisation to gastritis in these animals is not known. In a recent survey of the stomachs from 10 baboons (Papio spp.), only $C$. jejuni was isolated and gastritis was never observed (Baskerville and Newell, 1987).

The Rhesus monkey GCLO described here appears to be identical to $C$. pylori, and the histopathological evidence (Baskerville and Newell, 1987) suggests that colonisation of the monkey with this organism results in lesions similar to $C$. pylori-associated gastritis in man. This naturally acquired monkey infection may therefore provide an appropriate model for the study of human gastritis. Moreover, the source of infection may be easier to investigate in a closed primate colony.

monkey: a potential model for gastritis in man. Gut 29 : 465-472.

Blaser M J 1987 Gastric Campylobacter-like organisms, gastritis and peptic ulcer disease. Gastroenterology 93 : 371-383. 
Bronston M A, Schoenknecht F D 1988 Pylori campylobacter isolated from non-human primate stomach. In: Kaijser B, Falsen E (eds) Campylobacter IV, Proceedings of the IVth international workshop of campylobacter infections, Goteborg, June 1987, pp 340-341.

Fox J G, Edrise B M, Cabot E B, Beaucage C, Murphy J C, Prostak K S 1986 Campylobacter-like organisms isolated from gastric mucosa of ferrets. American Journal of Veterinary Research 47: 236-239.

Hudson M J, Bhavsar P, Wait R 1988 Chemotaxonomy of Campylobacters. In: Kaijser B, Falsen E (eds) Campylobacter IV, Proceedings of the IVth international workshop of campylobacter infections, Goteborg, June 1987, pp 3436.

Jones D M, Curry A, Fox A J 1985 An ultrastructural study of the gastric Campylobacter-like organism "Campylobacter pyloridis". Journal of General Microbiology 131 : 2335-2341.

Jones D M, Eldridge J 1988 Gastric Campylobacter-like organisms (GCLO) from man, ("Campylobacter pyloridis") compared with GCLO strains from the pig, baboon and ferret. In: Kaijser B, Falsen E (eds) Campylobacter IV, Proceedings of the IVth international workshop of campylobacter infections, Goteborg, June 1987, p 44.

Kyhse-Andersen J 1984 Electro-blotting of multiple gels: a simple apparatus without buffer tank for rapid transfer of proteins from polyacrylamide to nitrocellulose. Journal of Biophysical and Biochemical Methods 10: 203-209.

Marshall B J, Armstrong J A, McGechie D B, Glancy R J 1985 Attempt to fulfil Koch's postulates for pyloric Campylobacter. Medical Journal of Australia 142: 436-439.

Megraud F, Bonnet F, Garnier M, Lamouliatte H 1985
Characterization of "Campylobacter pyloridis" by culture, enzymatic profile and protein content. Journal of Clinical Microbiology 22: 1007-1010.

Morris A, Nicholson G 1987 Ingestion of Campylobacter pyloridis causes gastritis and raised fasting $\mathrm{pH}$. American Journal of Gastroenterology 82: 192-199.

Newell D G 1986 Monoclonal antibodies directed against the flagella of Campylobacter jejuni: cross-reacting and serotypic specificity and potential use in diagnosis. Journal of Hygiene 96: $377-384$.

Newell D G, McBride H, Pearson A D 1984 The identification of the outer membrane proteins and flagella of Campylobacter jejuni. Journal of General Microbiology 130: 1201-1208.

Newell D G 1987 Identification of the outer membrane proteins of Campylobacter pyloridis and antigenic cross-reactivity between Campylobacter pyloridis and Campylobacter jejuni. Journal of General Microbiology 133: 163-170.

Newell D G 1988 The production and characterisation of monoclonal antibodies directed against a species specific surface protein of $C$. pylori. In: Kaijser B, Falsen E (eds) Campylobacter IV, Proceedings of the IVth international workshop of campylobacter infections, Goteborg, June 1987, pp 115-116.

Owen R J, Martin S R, Borman P 1985 Rapid urea hydrolysis by gastric campylobacters. Lancet $1: 111$.

Skirrow M B 1977 Campylobacter enteritis: a "new" disease. British Journal of Medicine 2: 9-11.

Wait R, Hudson M J 1985 The use of picolinyl esters for the characterization of microbial lipids: application to the unsaturated and cyclopropane fatty acids of Campylobacter species. Letters in Applied Microbiology 1 : 95-99. 